\title{
Disorders of nutritional status in sepsis - facts and myths
}

\author{
Katarzyna Kosałka, ${ }^{1,2}$, Ewelina Wachowska ${ }^{1}$, Robert Słotwiński ${ }^{1,3}$ \\ 'Department of Immunology, Biochemistry, and Nutrition, Warsaw Medical University, Warsaw, Poland \\ ${ }^{2}$ Central Clinical Hospital of the Ministry of Interior and Administration, Warsaw, Poland \\ ${ }^{3}$ Department of Surgical Research and Transplantology, Mossakowski Medical Research Centre, Polish Academy of Sciences, \\ Warsaw, Poland
}

Key words: nutritional status disorders, malnutrition, sepsis, intensive care unit.

Address for correspondence: Katarzyna Kosałka MS, Central Clinical Hospital of the Ministry of Interior and Administration in Warsaw, 137 Wołoska St, 02-507 Warsaw, Poland, phone: +48 2250810 93, e-mail: katarzyna.kosalka@cskmswia.pl

\begin{abstract}
The problem of diagnosing nutritional status disorders in septic patients remains unresolved. This is associated with the necessity of the introduction of newer and newer methods of assessing nutritional status, often requiring precise and expensive equipment as well as employment of professionals in this field in hospital wards, primarily including intensive care units (ICU). Methods that have been applied thus far for assessing nutritional status, also used in severely ill septic patients, have little impact on improving treatment results. This is due to the high dynamics of changes in nutritional status in these patients, healing process variability in individual patients, and the "mismatch" of methods for assessing nutritional status in relation to the patient's clinical status. The diagnostic value of the traditional methods of assessing nutritional status, i.e. anthropometric analysis and selected laboratory tests, as markers of nutritional status disorders in septic patients, is still debatable. There is still no precise method that could become the "gold standard" allowing for early identification of malnutrition in these group of patients. Phase angle, bioelectrical impedance vector analysis (BIVA), and the "illness marker", obtained directly from the resistance, reactance, and impedance, can be used as prognostic or nutritional indices in severely ill septic patients, but the intensity of research on this subject needs to be increased. Detailed assessment of nutritional status should include tests of selected inflammation markers (including TLC, HMGB1, IL-6, IL-10, IL-1ra, sTNFRI).
\end{abstract}

\section{Introduction}

Although significant advances have been made in knowledge concerning the causes, prevalence, diagnosis, consequences, and treatment of malnutrition in everyday clinical practice, still little attention is paid to the professional evaluation of nutrition [1]. It should be stressed that malnutrition is an independent and the strongest, in addition to organ failure, risk factor of treatment complications and the patient's death. It occurs on average in $50 \%$ of septic patients treated in the intensive care unit (ICU) [2]. The consequence of malnutrition is extended treatment time (30-50\%), higher incidence of septic complications (15-30\%), respiratory and circulatory failure, and cardiac arrest, as well as increased mortality (30-60\%) [3]. Therefore, prevention of malnutrition and its treatment is an immensely important part of comprehensive patient care $[1,4]$.
Interpretation of nutritional status results in septic patients treated in ICU poses several difficulties. It is known that nutritional status disorders have a significant impact on the results of treatment and they should be carefully monitored in the group of malnourished septic patients requiring nutrition. Nutritional status disorders in septic patients treated in the ICU may result from starvation, absorption and digestion disorders, disturbed metabolism and prolonged increased systemic inflammatory response syndrome (SIRS) or compensatory antiinflammatory response syndrome (CARS), accompanying infections and multiple organ failure [5-7]. Despite the use of various therapeutic algorithms, severe infections and acute respiratory failure are still the main causes of death. Mortality in septic patients treated in the ICU is still the highest. In sepsis it is $16 \%$, and in severe sepsis $36 \%$, while in septic shock it is $58 \%[8,9]$. 
Difficult to compensate protein-calorie deficit, exacerbating in septic patients, can lead in a short time to persistent inflammation and immunosuppression and catabolism syndrome (PICS), burdened with high mortality. Simple clinical diagnostics of PICS is based on the identification of abnormal values of selected parameters (ICU stay $>10$ days, weight loss $>10 \%$ during hospitalisation or body mass index $(\mathrm{BMI})<18 \mathrm{~kg} / \mathrm{m}^{2}$, C-reactive protein $(C R P)>150 \mu \mathrm{g} / \mathrm{dl}$, total lymphocyte count $(\mathrm{TLC})<0.8 \times 10^{9} / \mathrm{l}$, albumin $<3.0 \mathrm{~g} / \mathrm{dl}$, transfer$\mathrm{rin} /$ prealbumin $<10 \mathrm{mg} / \mathrm{dl}$, retinol-binding protein (RBP) $<10 \mu \mathrm{g} / \mathrm{dl})[10,11]$. The results of these studies indicate the need for an appropriate therapeutic approach, taking into account the nutritional status improvement and reduction in protein catabolism, which requires close monitoring of nutritional status changes. The referred diagnostic test scheme did not include the assessment of multi-level "defects" of the immune response (inflammation) increasing the risk of severe infections and multiple organ failure.

Among the many factors hindering the evaluation of nutritional status, one should mention the development of the disease process (development of infection, organ failure, movement of fluids into the extravascular space, persisting hypercatabolism) and the treatment applied (reoperations in patients in severe condition, renal replacement therapy). The diagnostic value of selected tests (TLC, levels of albumin, transferrin, RBP, fibronectin, TTR - transthyretin/prealbumin, muscle proteolysis index, levels of selenium or glutamine, arginine, selectin, citrulline) as markers of nutritional status disorders in this group of patients is still debatable. Most of these tests are not routinely performed in the ICU [5]. However, simple anthropometric and laboratory methods, routinely applied to evaluate the nutritional status of chronically ill patients, are also used in severely ill septic patients. Heterogeneity in study groups and genetically determined variability of the inflammatory response to trauma, infection, or malnutrition are other problems hampering the evaluation and comparison of nutritional status in septic patients treated in the ICU. Expanding routine diagnostics of nutritional status by more accurate assessment of the inflammatory response based on the concentrations of proinflammatory and anti-inflammatory cytokines (IL-6, IL-10, IL-1ra, or sTNFRI) provide some hope [12]. It has been repeatedly proposed that the dynamics of the inflammatory response be controlled in severe infection on the basis of selected parameters of SIRS and CARS response (e.g. TNF- $\alpha$, IL-1, IL-6) [13]. Attention was also drawn to other prognostic factors, including genetic predisposition, type and source of infection, and degree of multiple organ failure, formulating on this basis a sepsis classification system (predisposition, insult/infection, response of the host system and organ dysfunction - PIRO staging system) [14]. This system (omitting nutritional status assessment) attempted to link selected genetic, immunological, and bacteriological markers with clinical signs of infection. However, it is still not precisely determined to what extent the inflammatory response parameters correlate with changes in the state of nutrition in these patients, the severity of their condition, and the results of treatment. The authors of many studies emphasise that the markers of nutritional status used in the ICU septic patients should be accurate, sensitive to its changes, possibly easy to apply, and reproducible. Unfortunately, there is no single marker that can be used to assess nutritional status in such a heterogeneous group of patients, i.e. septic patients requiring intensive care $[6,15$, 16]. Interpretation of test results is hampered by the high dynamics of nutritional status changes, variability of the recovery process in individual patients (wound healing, return to natural feeding), and the "mismatch" of methods for assessing nutritional status in relation to the clinical condition of the patient. There is still no precise method that could become the "gold standard" allowing for early identification of malnutrition in septic patients requiring intensive care $[17,18]$. Increasing employment of nutritionists in the ICU may be one practical solution because they, as members of professional therapeutic teams, will expertly verify the diagnostic usefulness of existing methods for assessing nutritional status, the value of laboratory indices of malnutrition, and the effectiveness of appropriate nutritional therapy (e.g. enhancing the immune system).

\section{Nutrition societies recommendations}

To assess nutritional status, experts of the American Society for Parenteral and Enteral Nutrition (ASPEN, 2002) recommend a screening assessment based on the SGA questionnaire and evaluation of: weight loss, nutrient intake level, disease severity, gastrointestinal tract function, and the presence of comorbidities. The SGA scale score significantly correlates with anthropometric measurements, high scores on disease severity scales (i.e. APACHE II and SAPS II), as well as with increased mortality of the patients [19]. An additional advantage of this scale is that it is not just a simple diagnostic tool, but it also identifies the risk of complications correlated with the nutritional status of severely ill patients. Experts believe that it is necessary to combine both clinical and biochemical parameters in order to diagnose malnutrition $[20,21]$. According to ASPEN, traditional methods for assessing nutritional status, i.e. anthropometry and measuring serum concentrations of proteins such as albumin, prealbumin, transferrin, and 
retinol-binding protein, have limited diagnostic value for severely ill septic patients requiring intensive care [21]. It should be emphasised that the reduced synthesis of these proteins in plasma may not only be a consequence of malnutrition, but also a disease, e.g. liver damage, kidney diseases, intestinal fistulas, exudative enteropathies, inflammatory bowel disease, extensive burns, exudates, transudates, and increased degradation during infection and diseases involving fever and increased metabolism. Therefore, the mutual interaction of malnutrition and inflammation in septic patients is an extremely complex and still poorly understood problem. One of the major drawbacks of this method is the lack of quantitative criteria because SGA is based on observer experience [5]. This scale is one of the two most commonly used screening scales (except NRS 2002) to identify malnutrition [22].

In 2003, the European Society for Clinical Nutrition and Metabolism (ESPEN) published standards for evaluating nutritional status in hospital wards. It was recommended that all adult patients, including septic patients, in every hospital ward, including the ICU, should undergo screening tests based on the NRS 2002 scale (Nutrition Risk Screening 2002) [23]. This scale has a high efficacy in predicting the course of disease in severely ill patients with sepsis, and according to different authors, it should be used within $48 \mathrm{~h}$ of admitting the patient to the ward $[4,24]$. Numerous studies have shown that the NRS 2002 scale positively correlates with the length of hospital stay, the incidence of postoperative complications, and increased mortality [4, 25-28].

We have shown in our own study on a group of 155 septic patients treated in the ICU that all of the four studied scales (two scales assessing nutritional status, and two scales of disease severity), i.e. SGA, NRS 2002, APACHE II, and SAPS II, were positively related to the occurrence of death. However, the highest discriminatory strength was found in the case of the NRS 2002 scale (Figure 1) [29]. The optimal cut-off point for NRS 2002 scale was 5.5 (sensitivity $=0.818$ and specificity $=0.705$ ), while for SGA -2.5 (sensitivity $=0.606$ and specificity $=0.721$ ).

According to the ESPEN experts, the risk of severe malnutrition occurs when at least one of the following criteria is present: weight loss over $10-15 \%$ within 6 months, $\mathrm{BMI}<18 \mathrm{~kg} / \mathrm{m}^{2}$, classification $\mathrm{C}$ in the subjective global assessment (SGA), and serum albumin < $30 \mathrm{~g} / \mathrm{l}$ (with no signs of liver or kidney disorders). In addition, ESPEN considers hypoalbuminaemia, of the laboratory tests, as reflecting inflammatory activity, and therefore representing a better risk factor for postoperative infectious complications and increased mortality than the sole state of malnutrition [30].

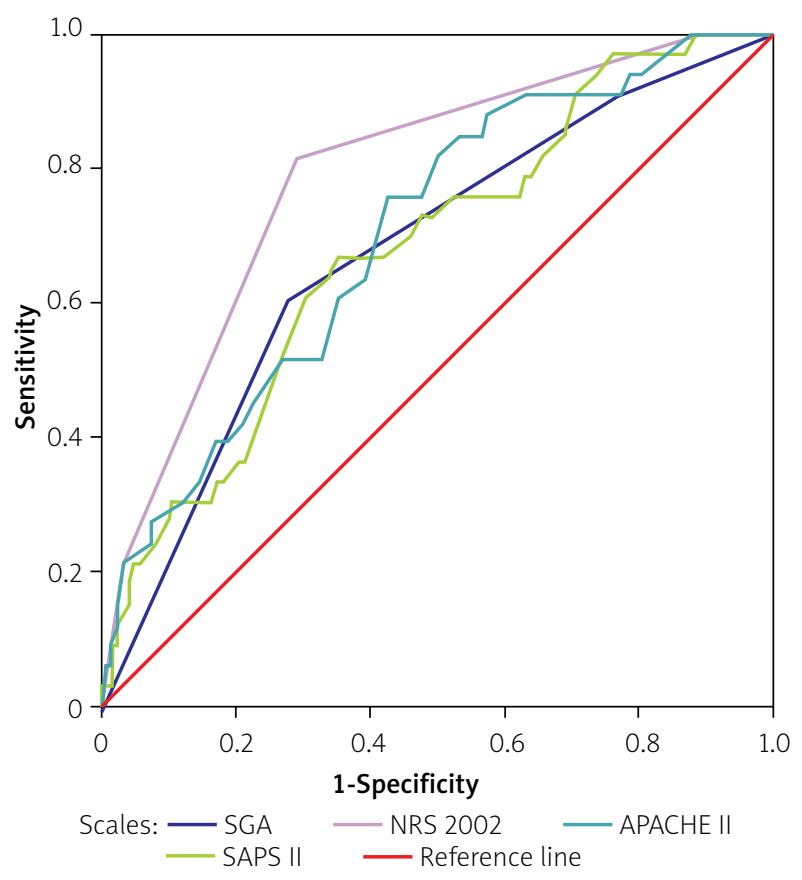

Figure 1. The receiver operating characteristic (ROC) curve - the positive relationship of 4 studied scales with the occurrence of death

In 2009, ASPEN and ESPEN developed common guidelines for diagnosing malnutrition in relation to the inflammatory response [31]. Malnutrition was divided according to three criteria: malnutrition associated with starvation, malnutrition associated with chronic disease, and malnutrition associated with acute inflammation. The societies determined that there is no single parameter based on which malnutrition can be identified. In order to detect malnutrition in septic patients treated in the ICU, who most likely suffer from malnutrition associated with acute inflammation, it is recommended that at least two of the six criteria included in Table I are determined [31]. It was emphasised that energy demand in severely ill septic patients treated in the ICU depends on the stage of the disease and nutritional status. Energy consumption in haemodynamically unstable patients should not exceed $30-50 \%$ of energy expenditure. As regards septic patients hospitalised for an extended time period in the ICU, with frequent exacerbations of catabolic processes, the energy requirement should be determined by measuring energy expenditure. Numerous studies have demonstrated that the estimation of energy requirements in critically ill patients with sepsis treated in the ICU is subject to very high overestimation error and requires individual assessment, preferably using indirect calorimetry [32]. The energy expenditure of patients requiring intensive care is often modified by various factors (patient immobilisation, lack of muscle activity, sedation, artificial 
Table I. Criteria for malnutrition in septic patients treated in ICU with acute inflammation

\begin{tabular}{lcc}
\hline Criterion & Moderate malnutrition & Severe malnutrition \\
\hline Energy supply & $\leq 75 \%$ energy supply for a minimum of 7 days & $\leq 50 \%$ energy supply for a minimum of 5 days \\
\hline Weight loss & $5 \%$ decrease within 1 month & $5 \%$ decrease within 1 month \\
\hline Adipose tissue loss & Mild decrease & Moderate decrease \\
\hline Muscle loss & Mild decrease & Moderate decrease \\
\hline Fluid retention & Mild increase & Moderate or high increase \\
\hline Muscle strength & Not applicable & Decreased
\end{tabular}

ventilation, different ways of nutrition or lack thereof, generalised inflammation, impaired excretion, multi-organ failure), and therefore its estimation using equations in this group of patients can lead to unacceptably large error [33]. In a randomised TICACOS trial, it was demonstrated that the supply of an adequate number of calories to patients, in relation to their energy expenditure, significantly decreased their mortality [34].

Since 1 January 2012, the Ministry of Health in cooperation with the Polish Society of Parenteral and Enteral Nutrition (POLSPEN), based on NRS 2002 and SGA scales, imposed the obligation to conduct a screening assessment of nutritional status of patients in all hospital wards, including ICUs (except for emergency departments - ED). A deepened evaluation of nutritional status according to the POLSPEN standards (2014) should be based on the analysis of anthropometry results and additional tests, i.e. age, height, current weight, complete blood count, serum electrolytes, urea, creatinine, glucose, albumin, triglycerides, and cholesterol levels. The following anthropometric and laboratory parameters should be additionally included in justified cases: arm muscle circumference, triceps skinfold thickness, transferrin and prealbumin concentrations, nitrogen balance, resting energy expenditure, respiratory rate, and body composition measurements [1].

\section{Importance of selected anthropometric index evaluations}

Anthropometric indices can be used for initial evaluation and detection of malnutrition, however, due to the too slow reaction of the system to changes in the supply of nutrients, they are of limited value in the daily monitoring of nutritional status. The evaluation of these parameters can be burdened with unacceptably large errors due to changes in hydration and hypoalbuminaemia $[35,36]$. This was confirmed in a trial conducted in the ICU that included a small group of patients with peritonitis and a history of large, blunt abdominal trauma. These authors observed that a loss of total protein in both groups was highest during the first 10 days (average of $13.1 \%$ ), while septic patients retained two times more water as compared with the group with a trauma history. It is known that in severely ill patients treated in the ICU, determination of body weight is very difficult and may be subject to errors due to the large dynamics of changes in hydration in a short period of time (lying patient, unconscious, connected to a ventilator) [37]. The body weight of the patient is the sum of protein, fat, water and bone mass in the body. When proportions of these components are changing, e.g. during increasing swellings, despite the deteriorating nutritional status, it may not undergo any significant changes or it may increase. Therefore, normal nutritional status, often identified with excessive body weight, may be misinterpreted in severely ill ICU patients [37]. A study by Mourilhe et al. showed that changes in body weight in septic patients, requiring intensive care, are more due to the body fluid movements than changes in nutritional status. In these studies, it was found that body weight losses greater than $10 \%$, acute or occurring in the past 6 months, indicating malnutrition, should not be considered as independent parameters in the assessment of nutritional status of septic patients in the ICU, which was also confirmed by other authors [5, 36].

Body mass index (BMI, calculated based on the quotient of patient body weight in $\mathrm{kg}$ and the square of their height in metres) gives information about the patient's nutritional status and the associated risk of disease development, complications, or death. Body mass index as well as the measurement of body weight in assessing the nutritional status of critically ill patients may be misinterpreted because of the changes in fluid balance caused by, among others, oedemas or use of diuretics [38]. It should be noted that BMI should be primarily used to identify malnourished patients admitted to the ICU, while it has little value in monitoring the nutritional status of septic patients [39]. 
Arm muscle circumference (AMC), which evaluates the arm muscle tissue reserves (not including the bone area), can be useful among other anthropometric parameters for assessing the nutritional status of patients and malnutrition identification. It is an easy, fast measurement that can be used at the bedside. However, it may be unreliable because of the increased fluid retention in the body of the ICU septic patient [39]. Arm muscle circumference below $15 \mathrm{~cm}$ in patients requiring intensive therapy may indicate chronic malnutrition, and thus increased risk of complications and mortality [40]. Similarly, measuring triceps skinfold thickness (TSF) and handgrip dynamometry do not apply in critically ill patients with sepsis treated in the ICU [41].

\section{The importance of body composition tests}

Due to the limited usefulness of anthropometric analysis and biochemical indices in assessing the nutritional status of severely ill patients, attempts are made to analyse body composition using bioelectrical impedance analysis (BIA), evaluating the fat content and lean body mass using the electrical properties of the organism and varying impedance of particular tissues to electric current. By measuring the BIA, one can specify, among others, the content of lean body mass, total water content, total cell mass, and extracellular and intracellular mass. Bioelectric impedance is a measure of electrical resistance of the body, i.e. the total "obstacle" that body tissues represent for the current flowing through them, expressed in ohms. It consists of passive resistance or otherwise capacitive resistance, known as reactance $(X)$, and active resistance, known simply as resistance ( $R)$. The resistance of the tissues is primarily dependent on the resistance of cell membranes. Adipose tissue and extracellular water are the tissues demonstrating active resistance. The reactance, in turn, is formed on the cell membranes of tissues with high water content, which due to its structure acts as a capacitor $[42,43]$. A study performed in a group of 109 patients after gastrointestinal surgery showed that the impedance is a good indicator of malnutrition [44]. Contraindications to this method include burns, haemodialysis, low-flow shock, resuscitation, pacemaker, conduction disorders, endoprosthesis of conductive materials, and pregnancy. Another problem with BIA is the lack of measurement standardisation for different ethnic groups and clinical situations [45]. Single frequency BIA (SF-BIA) measures the impedance at $50 \mathrm{kHz}$ and allows determination of the total body water (TBW) and fat free mass (FFM) using empirical regression equations. This method is applicable in healthy humans. Multi-frequency BIA (MF-BIA) measures the impedance using dif- ferent frequencies, depending on the device. This method is more accurate in assessing the ECW than SF-BIA, particularly in critically ill septic patients. The "illness marker" (IM) is a measurement obtained using MF-BIA, which serves as a functional marker of cell membranes, as well as the mortality rate of ICU patients. A study in a group of 85 patients requiring intensive care found that the IM significantly correlated with APACHE scores. The IM and APACHE were both significantly higher in patients who died than in survivors [46].

The relationship between resistance and reactance can be represented graphically as an impedance vector forming a phase angle (PA), which is considered a global marker of tissue health. This is a good marker of body cell mass and the integrity and function of cell membranes. The PA is altered when cell membrane permeability changes, even when the cell mass remains the same. Many studies have shown that the phase angle is a reliable prognostic marker in many clinical situations, e.g. sepsis, HIV infection, lung and colorectal cancers, patients requiring intensive care, patients with chronic liver diseases, and after transplantation $[47,48]$. Other works observed that the PA correlates with nutritional status in surgical patients and the elderly $[49,50]$. Norman et al. observed that oncology patients with phase angle below $5^{\circ}$ had poorer nutritional status and increased mortality [51]. Moreover, Kyle et al. found a relationship between the low value of phase angle and the length of treatment and severity of malnutrition in patients hospitalised for various reasons [52]. Earlier studies found that the ICU patients with APACHE II scores above 20 points and PA $>4$ had a better chance of survival compared to patients with PA $<3$ [53]. Other authors found in a group of 225 gastroenterology patients requiring surgery a positive correlation between the phase angle, weight loss $>10 \%$, SGA, and NRS 2002 scales, the ratio of extracellular to cellular mass (ECM/BCM), and the incidence of postoperative complications [49]. A study in a group of 52 patients with colorectal cancer found that a PA less than or equal to 4.50 significantly correlated with shorter survival compared to patients with higher PA (above 4.50) [54]. Peres et al. found that PA positively correlated with SGA and OMR scales and serum albumin levels, and negatively with age [55]. Although earlier studies confirmed the use of PA as a prognostic marker in sepsis, in surgical patients, and in those treated in the ICU, this index is not routinely used in the ICU. At present, the number of studies indicating a practical usefulness of the PA assessment in critically ill patients as a marker of disease severity, malnutrition, monitoring of nutritional therapy, or prognostic marker is still insufficient $[47,51]$. 
The BIVA, i.e. bioelectrical impedance vector, is another method, proposed by Piccoli (2002), of interpreting the information obtained based on BIA. A two-dimensional impedance vector is determined using resistance and reactance at $50 \mathrm{kHz}$, after normalisation to the height of the patient. Individual measurements can be compared to confidence intervals (elliptical shape) determined for the healthy population. The vector shift over the ellipse is a semi-quantitative method of assessing body composition, while shortening or lengthening of the vector suggests changes in body hydration. The BIVA can be applied in patients treated in the ICU, because abnormal states of hydration often occur in this group of patients, i.e. oedema, ascites, dehydration [45].

In our own study, in a group of 51 septic patients treated in the ICU, indicated that approximately $49 \%$ of septic cases exceeded the $50^{\text {th }}$ percentile. These patients were situated in the lower left quadrant, indicating their overhydration (Figure 2) [56].

Bioelectrical impedance spectroscopy (BIS) makes use of 50 or more frequencies during the measurement. Relationships between reactance and resistance at different frequencies are used to extrapolate from zero to infinity. These values are applicable in calculating the resistance for extracellular water (ECW) and intracellular water (ICW). The volume of fluid spaces can be calculated using those resistances based on empirical equations. Similarly to the MF-BIA analysis, this method can be used in patients with hydration disorders.

Body cell mass (BCM) is another marker of nutritional status. It was shown that the low BCM level positively correlated with reduced energy and protein supply in the ICU patients (group of 33 patients). Moreover, the reduction of $B C M$, in the study group of severely ill malnourished patients reached as much as $40 \%$ compared to healthy subjects [42]. The ratio of extracellular mass (ECM) to BCM was closely correlated with the occurrence of bacterial infections in severely ill malnourished patients with HIV [57].

Many studies have proven that the bioelectrical impedance analysis, and in particular the results of the raw physical data (i.e. impedance, resistance, reactance, or phase angle) provide valuable information of prognostic importance in critically ill patients [43]. The ICU patients often have fluid balance disorders, including the movement of fluids from the intra- to extravascular space. Some researchers have demonstrated mitochondrial disorders in the cells of septic patients that can accelerate their apoptosis. Raw physical data depict exactly these changes: reactance results may be indicative of cell condition, while the resistance of existing oedemas. Recently, a study of 332 critically ill children with multiple organ failure, mechanically ventilated, highlighted the use of resistance and reactance in clinical practice and vector impedance analysis in the assessment of

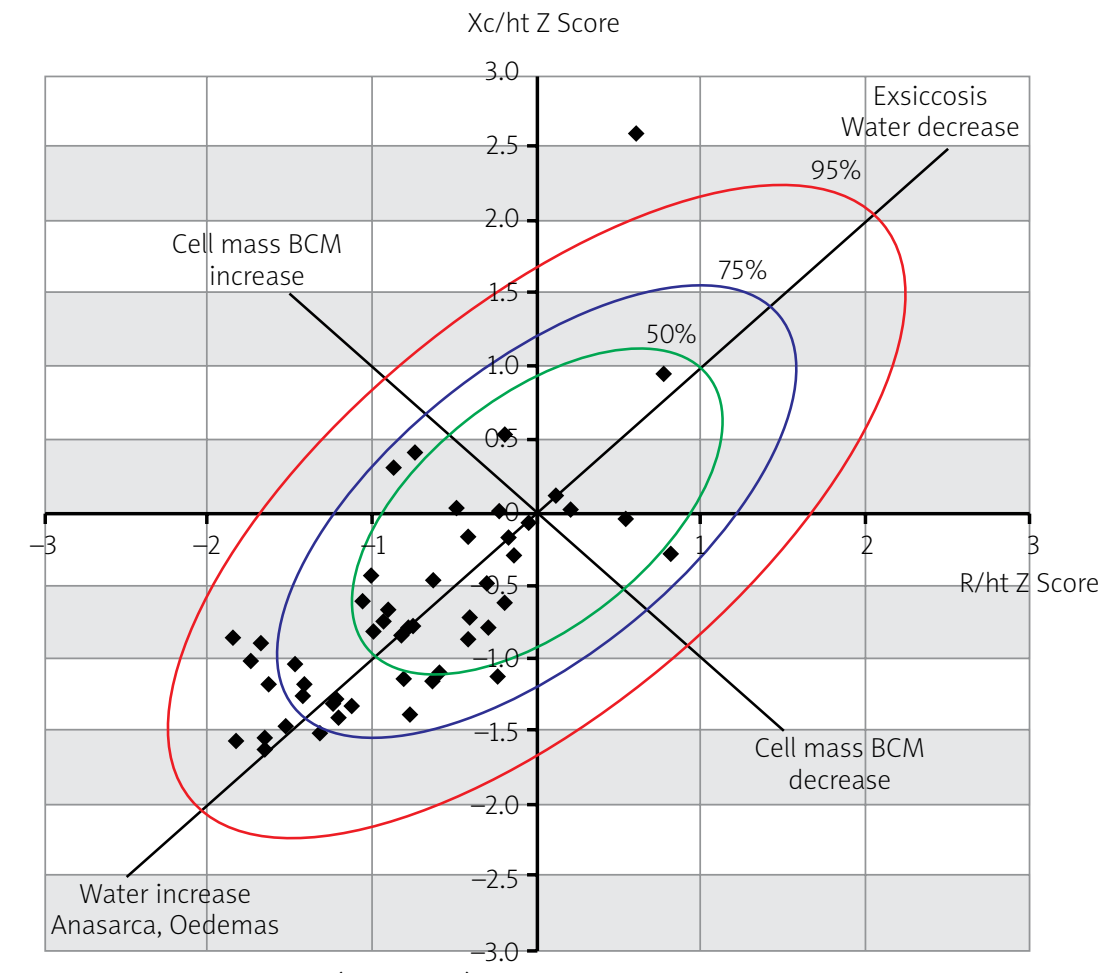

Figure 2. Analysis of vector impedance (BIA chart) in septic patients 
severity of the patient's condition. This study showed a significant increase in the value of reactance and resistance in children who survived compared with children who had died and showed a noticeable decrease in these values [58].

Among other parameters important in assessing the nutritional status of critically ill patients, increasing attention is paid to sarcopenia, which is a very common phenomenon among patients requiring intensive care. In a recent study involving a group of 149 severely injured ICU patients ( $>55$ years of age), sarcopenia was detected in as many as $71 \%$ of subjects [59]. In this study, low muscle mass, measured using CT, significantly correlated with the time of ventilator connection, longer hospitalisation in the ICU, and higher mortality.

\section{Selected biomarker analysis}

Biochemical markers have been repeatedly used for objective assessment of nutritional status [60]. However, it is known that they have no practical use as independent markers [6]. Currently, their value in the clinical assessment of nutritional status is limited. This particularly pertains to proteins measured in serum (e.g. albumin, prealbumin, transferrin) [61]. It should be noted that in addition to the nutritional value of the diet, there are many factors that modify the concentration of serum proteins (e.g. stage of disease development, liver disease, kidney disease, changes in hydration, high catabolism, loss of proteins, infection, inflammation) $[62,63]$. The evaluation of known biomarkers: insulin-like growth factor (IGF-1), citrulline and glutamine or arginine is not routinely performed, particularly in the wards such as ICU, although it is known that malnutrition is accompanied by a reduction in these parameters. As malnutrition primarily lowers the cell-mediated immunity, total lymphocyte count (TLC) in $1 \mathrm{~mm}^{3}$ of peripheral blood is still the most common immunoassay performed in the ICU. However, it should be noted that in addition to nutritional status, the level of this indicator is also affected by other factors, including current disease (e.g. cancer), acute inflammation, infection, and medications used. This test is entirely non-specific and is merely a screening.

High mobility group box-1 protein (HMGB1), a protein secreted by cells of the immune system (e.g. macrophages, monocytes, and dendritic cells), is among the recently mentioned markers of the inflammatory response to malnutrition. Lai et al. showed that high concentrations of this protein positively correlated with the severity of disease and mortality of ICU patients with severe pneumonia. HMGB1 protein is an "alarmin" released under the influence of LPS during infection. This protein activates macrophages, which leads to the release of pro-inflammatory cytokines and chemokines, it regulates fibrinolysis, and in the intestines it enhances the production of nitric oxide and increased permeability of the intestinal barrier [64].

Disorders of nutritional status affect most mediators of the immune system, in particular by impairing the cellular response and resistance to infection. Hypoalbuminaemia, resulting from inflammation, disturbs the metabolism of cytokines (including IL-6, IL-10, IL-1ra, and STNFRI). The consequence of impaired immunity is increased susceptibility to infection and reduced ability of "adequate" response to trauma. An increase in the concentration of proinflammatory cytokines (e.g. IL-6) is observed in most patients treated in the ICU. Interleukin- 6 is one of the most important cytokines, acting multidirectionally, secreted mainly by monocytes and macrophages under the influence of IL-1 and other pro-inflammatory cytokines. On the one hand, it strongly induces inflammatory processes (major mediator of the acute phase response) and stimulates the synthesis of acute phase proteins (CRP, amyloid A, $\beta$-fibrinogen, $\alpha 1$-antitrypsin, haptoglobin, ceruloplasmin, complement component C3 and $\alpha 2$-antitrypsin), while on the other hand, it is involved in feedback inhibition of TNF production. IL-6 is considered to be an early SIRS marker. A study by Honda et al. on a group of 1076 critically ill patients with renal failure (stage 4) found that high levels of IL- 6 were significantly more frequent in malnourished patients (classified by the SGA scale). There was also a positive correlation observed between the level of this biomarker in serum and increased mortality of these patients [65].

Interleukin-10 (IL-10) should be listed among other biomarkers of inflammation, secreted during the acute CARS response, which inhibit the production of proinflammatory cytokines, such as: interferon- $\gamma, \mathrm{IL}-2, \mathrm{IL}-3$, TNF- $\alpha$, or granulocyte macrophage colony-stimulating factor (GM-CSF). It is mainly produced by macrophages, dendritic cells, B cells, and Treg cells. It has both immunosuppressive and immunostimulating properties towards immune system cells. A study by Tseng et al. conducted on a group of 56 patients with severe pneumonia and acute respiratory distress syndrome (ARDS), treated in the ICU, recorded low levels of IL-10 on days 1 and 3 of the trial in patients who survived $(n=40)$, and high level of this interleukin on day 3 in those patients who died ( $n=16$ ) [66]. Another study conducted in a group of 34 patients with acute pancreatitis (AP) demonstrated significantly higher levels of IL-10 and IL- 6 on days 1 an 3 of treatment in patients who also had severe acute pancreatitis $(n=13)$, while the highest levels of both biomarkers were found in the patients who died. The authors of the latter study observed that 
the determination of serum IL-6 and IL-10 had a high prognostic value with respect to severe acute pancreatitis and death caused by this condition [67]. The above immunological studies did not perform parallel evaluations of patient nutritional status, which should be considered an error because of the potential influence of malnutrition on the body's inflammatory response.

\section{Conclusions}

In everyday clinical practice, despite significant progress of knowledge concerning the causes, prevalence, diagnosis, consequences, and treatment of malnutrition, little attention is paid to professional assessment of nutritional status. Interpretation of the results of nutritional status in critically ill septic patients poses a specific problem. It is known that disorders of nutritional status have a significant impact on the results of treatment, and they should be carefully monitored in the group of malnourished ICU patients with sepsis requiring nutrition. Interpretation of the results is hampered by the high dynamics of changes in the nutritional status in these patients, the healing process variability in individual patients (wound healing, return to natural nutrition and physical activity) and the "mismatch" of methods assessing nutritional status in relation to the clinical condition of the patient. There is still no precise method that could become the "gold standard" allowing early identification of malnutrition in the group of patients requiring intensive care. The diagnostic value of the traditional methods of assessing nutritional status, i.e. anthropometric tests (including measurements of weight or body loss, BMI, TSF, AMC, handgrip dynamometry) and selected laboratory tests, as markers of nutritional status disorders, is still debatable in this group of patients. Phase angle, BIVA, and the "illness marker" obtained directly from the resistance, reactance, and impedance can be used as prognostic or nutritional indices in severely ill septic patients when it is not possible to use the regression equations for the assessment of body weight; however, the intensity of research on this subject needs to be increased. In-depth assessment of nutritional status should include analyses of selected inflammation markers.

\section{Conflict of interest}

The authors declare no conflict of interest.

\section{References}

1. Pertkiewicz M, Korta T, Bogucki K, et al. Ocena stanu odżywienia. In: Standardy żywienia pozajelitowego i żywienia dojelitowego. Pertkiewicz M, Korta T (eds). PZWL, Warsaw 2014; 32-7.

2. Quirk J. Malnutrition in critically ill patients in intensive care units. Br J Nurs 2000; 9: 537-41.
3. Blanckenberg C. Determination of the most effective nutritional risk screening tool to predict clinical outcomes in intensive care unit patients. Thesis presented in partial fulfilment of the requirements for the degree of Master of Nutrition in the Faculty of Health Sciences Stellenbosch University 2012; 6.

4. Raslan M, Gonzalez MC, Dias MC, et al. Complementarity of Subjective Global Assessment (SGA) and Nutritional Risk Screening 2002 (NRS 2002) for predicting poor clinical outcomes in hospitalized patients. Clin Nutr 2011; 30: 49-53.

5. Steffek M, Lammek J. Leczenie żywieniowe w intensywnej terapii. In: Intensywna terapia. Wujtewicz M, Kwiecińska B (eds), Akademia Medyczna w Gdańsku, Gdańsk 2005; 147-63.

6. Maicá AO, Schweigert ID. Nutritional assessment of severely ill patient. Rev Bras Ter Intensiv 2008; 20: 286-95.

7. Fuhrmann K, Panamonta N, Shelley Roaten S. Malnutrition in the ICU: current recommendations for the assessment of nutritional status and a review of the use of albumin as an indicator of malnutrition. South Respir Crit Care Chron 2013; 1: 8-14.

8. Kübler A. Intensywna terapia - postępy 2011. Med Prakt 2012; 5: 46-51.

9. Kübler A. Sepsa i wstrząs septyczny. In: Choroby wewnętrzne. Szczeklik A (ed). Medycyna Praktyczna, Krakow 2005; 2: 2063-8.

10. Gentile LF, Cuenca AG, Philip AE, et al. Persistent inflammation and immunosuppression: a common syndrome and new horizon for surgical intensive care. J Trauma Acute Care Surg 2012; 72: 1491-501.

11. Hotchkiss RS, Monneret G, Payen D. Immunosuppression in sepsis: a novel understanding of the disorder and new therapeutic approach. Lancet 2013; 13: 260-8.

12. Słotwiński R, Szczygieł B, Szabłowski A, et al. Polish Changes in interleukin 6 and cytokine antagonists (IL-1ra and sTNFRI) serum concentration in patients after esophagectomy for esophageal cancer receiving nutritional support both pre- and postoperatively. Pol Oncol 2004; 7: 169-76.

13. Riedemann NC, Guo RF, Ward PA. The enigma of sepsis. J Clin Invest 2003; 112: 460-7.

14. Levy MM, Fink MP, Marshall JC, et al. 2001 SCCM/ESICM/ACCP/ ATS/SIS International Sepsis Definition Conference. Intens Care Med 2003; 29: 530-8.

15. Kreymann KG, Berger MM, Deutz NEP, et al. ESPEN guidelines on enteral nutrition: intensive care. Clin Nutr 2006; 25: 210-23.

16. Ryu SW, Kim IH. Comparison of different nutritional assessments in detecting malnutrition among gastric cancer patients. World J Gastroenetrol 2010; 16: 3310-7.

17. Valero MA, Diez L, Kadaoui NE, et al. Are the tools recommended by ASPEN and ESPEN comparable for assessing the nutritional status? Nutr Hosp 2005; 20: 259-67.

18. Velasco C, Garcia E, Rodriguez V, et al. Comparison of four nutritional screening tools to detect nutritional risk in hospitalized patients: a multicentre study. Eur J Clin Nutr 2011; 65: 269-74.

19. Sungurtekin H, Sungurtekin U, Oner O, et al. Nutrition assessment in critically ill patients. Nutr Clin Pract 2008; 23: 635-41.

20. ASPEN Board of Directors. Guidelines for use of parenteral, enteral nutrition in adult and pediatric care. J Parenter Enteral Nutr 2002; 26: 9-12. 
21. McClave SA, Martindale RG, Vanek VW, et al. Guidelines for the provision and assessment of nutrition support therapy in the adult critically ill patient: Society of Critical Care Medicine (SCCM) and American Society for Parenteral and Enteral Nutrition (A.S.P.E.N.). J Parenter Enteral Nutr 2009; 33: 277-316.

22. Ozkalkanli MY, Ozkalkanli DT, Katricioglu K, et al. Comparision of tools for nutrition assessment and screening for predicting the development of complications in orthopedic surgery. Nutr Clin Pract 2009; 24: 274-80.

23. Kondrup J, Rasmussen $\mathrm{HH}$, Hamberg O, et al. ESPEN working group. Nutritional risk screening (NRS 2002): new method based on an analysis of controlled clinical trials. Clin Nutr 2003; 22: 321-36.

24. Kondrup J, Allison SP, Elia M, et al. ESPEN Guidelines for Nutrition Screening 2002. Clin Nutr 2003; 22: 415-21.

25. Matos LC, Tavares MM, Amaral TF. Handgrip strength as a hospital admission nutritional risk screening method. Eur J Clin Nutr 2007; 61: 1128-35.

26. Schiesser M, Muller S, Kirchhoff P, et al. Assessment of a novel screening score for nutritional risk in predicting complications in gastro-intestinal surgery. Clin Nutr 2008; 27: 565-70.

27. Guo W, Ou G, Li X, et al. Screening of the nutritional risk of patients with gastric carcinoma before operation by NRS 2002 and its relationship with postoperative results. J Gastroenterol Hepatol 2010; 25: 800-3.

28. Schwegler I, von Holzen A, Gutzwiller JP, et al. Nutritional risk is a clinical predictor of postoperative mortality and morbidity in surgery for colorectal cancer. Br J Surg 2010; 97: 92-7.

29. Kosałka K, Wachowska E, Milewska M, et al. Znaczenie wybranych wskaźników oceny stanu odżywienia oraz parametrów immunologicznych u ciężko chorych z zakażeniami leczonych w oddziale intensywnej terapii. Adv Clin Nutr 2015; 2: 59.

30. Weimann A, Braga M, Harsanyi L, et al. ESPEN guidelines on enteral nutrition: surgery including organ transplantation. Clin Nutr 2006; 25: 224-44.

31. White JV, Guenter P, Jensen G, et al. Consensus Statement: Academy of Nutrition and Dietetics and American Society for Parenteral and Enteral Nutrition: characteristics recommended for the identification and documentation of adult malnutrition (undernutrition). J Acad Nutr Diet 2012; 112: 730-8.

32. Martins MA, Meneguet MG. Energy expenditure in critically ill surgical patients. Comparative analysis of predictive equation and indirect calorimetry. Acta Cir Bras 2011; 26 (Suppl. 2): 2011-51.

33. Dickerson RN. Optimal caloric intake for critically ill patients: first, do no harm. Nutr Clin Pract 2011; 26: 48-54.

34. Singer P, Anbar R, Cohen J, et al. The tight calorie control study (TICACOS): a prospective, randomized, controlled pilot study of nutritional support in critically ill patients. Inten Care Med 2011; 37: 601-9.

35. Acosta EJ, Gomez-Tello V, Ruiz SS. Nutritional assessment of the severely ill patient. Nutr Hosp 2005; 20 Suppl.: 5-8.

36. Plank LD, Hill GL. Similarity of changes in body composition in intensive care patients following severe sepsis or major blunt injury. Ann NY Acad Sci 2000; 904: 592-602.

37. Campillo B; Paillaud E, Uzan I, et al. Value of body mass index in the detection of severe malnutrition: influence of the pa- thology and changes in anthropometric parameters. Clin Nutr 2004; 23: 551-9.

38. Kuciel G, Łysiak-Szydłowska W. Metody oceny niedożywienia i efektywności terapii żywieniowej. Anest Intens Ter 2001; 1 : 29-33.

39. Chan S, McCowen KC, Blucburn GL. Nutrition management in the ICU. Chest 1999; 115: 145-9.

40. Ravasco P, Camilo ME, Gouveia-Oliveira A, et al. A critical approach to nutritional assessment in critically ill patients. Clin Nutr 2002; 21: 73-7.

41. Patton $H$, Park F. Nutritional assessment and management. Core Curriculum Lecture 2010; 1-16.

42. Robert S, Zarowitz BJ, Hyzy R, et al. Bioelectrical impedance assessment of nutritional status in critically ill patients. Am J Clin Nutr 1993; 57: 840-4.

43. Selberg O, Selberg D. Norms and correlates of bioimpedance phase angle in healthy human subjects, hospitalized patients, and patients with liver cirrhosis. Eur J Appl Physiol 2002; 86: 509-16.

44. Plank LD, Li A. Bioimpedance illness marker compared to phase angle as a predictor of malnutrition in hospitalised patients. Clin Nutr 2013; 32: S85.

45. Gonzalez MC, Nim LA, Rejven PLM, et al. Metoda bioelektrycznej impedancji. In: Podstawy żywienia klinicznego. Sobotka $L$ (ed). Scientifica, Warsaw 2013; 15-22.

46. Gonzalez MC, Masonek J, Uliano GL, et al. Illness marker as a prognostic tool in intensive care unit: a prospective study. J Parenter Enteral Nutr 2009; 33: 219.

47. Kyle UG, Bosaeus I, Lorenzo ADD, et al. Bioelectrical impedance analysis - part II: utilization in clinical practice. Clin Nutr 2004; 23: 1430-53.

48. Mialich MS, Faccioli Sicchieri JM, Jordao AA. Analysis of body composition: a critical review of the use of bioelectrical impedance analysis. Int J Clin Nutr 2014; 2: 1-10.

49. Barbosa-Silva MC, Barros AJ. Bioelectric impedance and individual characteristics as prognostic factors for post-operative complications. Clin Nutr 2005; 24: 830-8.

50. Norman K, Smoliner C, Valentini L, et al. Is bioelectrical impedance vector analysis of value in the eldery with malnutrition and impared functionality? Nutr 2007; 23: 264-9.

51. Norman K, Stobaus N, Pirlich M, et al. Bioelectrical phase angle and impedance vector analysis - clinical relevance and applicability of impedance parameters. Clin Nutr 2012; 31 : 854-61.

52. Kyle UG, Soundar EP, Genton L, et al. Can phase angle determined by bioelectrical impedance analysis assess nutritional risk? A comparison between healthy and hospitalized subjects. Clin Nutr 2012; 31: 875-81.

53. Mueller C, Compher C, Ellen DM. ASPEN clinical guidelines. Nutrition screening, assessment, and intervention in adults. J Parenter Enteral Nutr 2011; 35: 15-24.

54. Gupta D, Lammersfeld CA, Burrows JL, et al. Bioelectrical impedance phase angle in clinical practice: implications for prognosis in advanced colorectal cancer. Am J Clin Nutr 2004; 80: 1634-8.

55. Peres WAF, Lento DF, Baluz K, et al. Phase angle as a nutritional evaluation tool in all stages of chronic liver disease. Nutr Hosp 2012; 27: 2072-8. 
56. Słotwiński R, Milewska M, Kosałka K, et al. Raw impedance data analysis in severe ill patients with sepsis. Fluids 2013 2: 168-70.

57. Schwenk A, Steuck H, Kremer G. Oral supplements as adjunctive treatment to nutritional counseling in malnourished HIV infected patients: randomized controlled trial. Clin Nutr 1999; 18: 371-4.

58. Azevedo ZM, Moore DC, de Matos FA, et al. Bioelectrical impedance parameters in critically ill children: importance of reactance and resistance. Clin Nutr 2013; 32: 824-9.

59. Moisey LL, Mourtzakis M, Cotton BA, et al. Skeletal muscle predicts ventilator-free days, ICU-free days, and mortality in elderly ICU patients. Crit Care 2013; 17: R206.

60. Montejo GJC, Culebras-Fernandez JM, Garcia LMA. Recommendations for the nutritional assessment of critically ill patients. Rev Med Chile 2006; 134: 1049-56.

61. Myron JA, Merlini G, Sheldon J, et al. Clinical indications for plasma protein assays: transthyretin (prealbumin) in inflammation and malnutrition. Clin Chem Lab Med 2007; 45: 419-26.

62. Sullivan DH. What do the serum proteins tell us about our elderly patients? J Gerontol A Biol Sci Med Sci 2001; 56: M71-4

63. Sullivan DH, Roberson PK, Johnson LE, et al. Association between inflammation-associated cytokines, serum albumins, and mortality in the elderly. J Am Med Dir Assoc 2007; 8: 458-63.

64. Lai PF, Cheng CF, Lin H, et al. ATF3 protects against LPS-induced inflammation in mice via inhibiting HMBG1 expression. Evid Based Complement Altern Med 2013; 2013: ID 716481.

65. Honda H, Quereshi AR, Heimburger O, et al. Serum albumin, C-reactive protein, interleukin 6 , and fetuin $A$ as predictors of malnutrition, cardiovascular disease, and mortality in patients with ESRD. Am J Kidney Disease 2006; 47: 139-48.

66. Tseng C, Fang WF, Leung SY, et al. Impact of serum biomarkers and clinical factors on intensive care unit mortality and 6-month outcome in relatively healthy patients with severe pneumonia and acute respiratory distress syndrome. Dis Markers 2014; 2014: ID 804654

67. Cielecka J, Badowski J, Cywiński J, et al. Evaluation of interleukin 6 and interleukin 10 serum levels in patients with acute pancreatitis. Pol Surg 2004; 6: 222-9.

Received: 21.03.2016

Accepted: 28.03 .2017 